\title{
Alpha Glutathione S-transferase - A Potential Biomarker for Intestinal Epithelial Damage in Infants with Acute Gastroenteritis
}

\author{
Marija Dimitrovska-Ivanova ${ }^{1 *}$, Elizabeta Zisovska ${ }^{2}$ \\ ${ }^{1}$ Department of Pediatrics, Clinical Hospital - Shtip, Shtip, Republic of Macedonia; ${ }^{2}$ University Clinic for Gynecology and \\ Obstetrics, Skopje, Republic of Macedonia
}

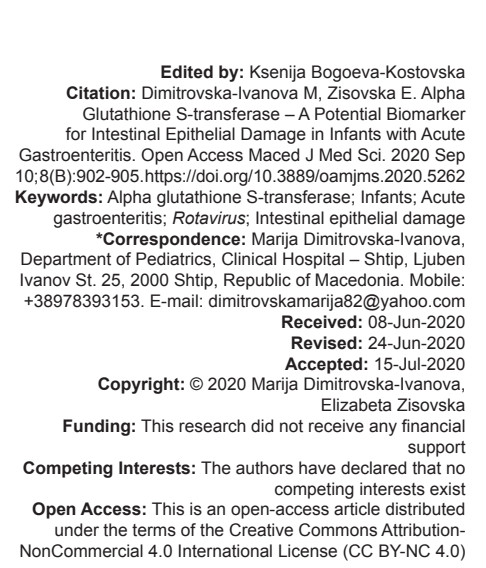

\section{Introduction}

Acute gastroenteritis is a leading cause of morbidity and mortality in developing and undeveloped countries where malnutrition and poor local health care are responsible for the worsening of the clinical signs of acute gastroenteritis [1]. Acute gastroenteritis is defined as a decrease in stool consistency and/or an increase in the frequency of discharges ( $\geq 3$ in $24 \mathrm{~h}$ ) with or without fever and vomiting [2]. Acute diarrhea lasts between 7 and 14 days [2]. The incidence of acute gastroenteritis ranges from 0.5 to 2 episodes per child per year in children under 3 years of age. At this age, acute gastroenteritis is the most common cause of hospitalization [2]. Acute gastroenteritis can be especially dangerous in the first 6 months of life with a higher risk of increased water and electrolyte loss with consequent moderate to severe dehydration, especially in infants who are not exclusively breastfed. Rotavirus is the most common cause of acute gastroenteritis; rarer causes are Adenovirus, Norovirus, and Astrovirus. Bacterial pathogens include Salmonella, Shigella, and less commonly Escherichia coli, Campylobacter jejuni, and Yersinia enterocolitica. Enterocyte infection leads to cell death, lumen extrusion, and atrophy of the intestinal villi, resulting in reduced intestinal surface area, with impaired digestive and absorption functions and acute transient malabsorptive diarrhea.

The mucosal barrier can be compromised as a result of various intestinal diseases and as such can play a major role in the pathogenesis and maintenance of the disease [3]. Intestinal epithelial barrier dysfunction increases intestinal mucosal permeability. As a result, intestinal bacteria, endotoxins, and other harmful substances pass through the intestinal tissue and initiate a series of pathophysiological changes and even a systemic inflammatory response and multiorgan dysfunction syndrome [4]. Although there has been progress in tests that assess the function of the intestinal epithelial barrier, the evaluation of the integrity and function of the intestinal epithelium for clinicians remains challenging [3]. The intestinal mucosa is involved in the digestion and absorption of nutrients, in the protection against infectious, toxic, and carcinogenic substances ingested in the digestive tract. For this purpose, a complex defense system is involved: Mucosal barrier, epithelial cells with short life (several days), which have a complex enzyme system capable of metabolizing harmful substances 
in a way that allows their excretion through the bile, stool, and urine. One of the most important classes of enzymes that perform this function is glutathione S-transferase (GST) enzymes. They are involved in binding, transporting, and detoxifying these harmful substances by binding them to glutathione (GSH) [5]. Kelly et al. 2004 [6] demonstrated that the GSH detoxification system is important in maintaining the integrity of the intestinal mucosa. According to Kong et al. 2019 [4] and Coles et al. 2002 [7], alpha GST $(\alpha-G S T)$ is isoform of GST enzymes and is a highly active structural enzyme in intestinal mucosal epithelial cells, although it is also present in the liver and kidneys [5].

\section{Materials and Methods}

\section{Study design}

This was a prospective cohort study conducted from November 15, 2018 until the end of December, 2019. The study included newborns and infants from birth to 6 months of age who were diagnosed with acute gastroenteritis. All infants were hospitalized at the Children's Department in Clinical Hospital - Shtip. Parents' written consent was obtained for each infant included in the study after extensive communication with them. An appropriate survey questionnaire was designed and responses were obtained from the infants' mothers. The questionnaire covered the following segments: Infant age, nutrition (breast milk, milk formula, or cow's milk), and weaning practice. Infants were divided into two groups according to age in months and according to milk nutrition.

Group I included newborns and infants from birth to 6 months who were exclusively breastfed. Group II included newborns and infants from birth to 6 months of age who were not exclusively breastfed and were on mixed milk nutrition.

Exclusively breastfed were infants who were fed only with breast milk and did not receive additional food or fluids (excluding oral rehydration solution, vitamins, minerals, and medications).

The study did not include infants whose diarrhea was due to a surgical or extraintestinal cause, as well as infants who had received immunosuppressive therapy.

\section{Laboratory methods}

From each infant included in the study, one sample of diaper stool was taken with a plastic spatula. This stool sample was collected in a sterile plastic cup with the general data of the patient and the code written on it and within $30 \mathrm{~min}$ it was brought to the Microbiological Laboratory in the Center for Public Health (CPH) - Shtip. In this stool sample, the presence of Rotavirus and Adenovirus with Immunochromatographic test (DUO ROTAADENOVIRUS - Check-1 VEDA.LAB, AlenconFrance) was analyzed. From the same stool sample, a coproculture was performed which disproved the presence of enteropathogenic bacteria by sowing the stool sample on a suitable substrate.

From each infant $2.5 \mathrm{ml}$, venous blood was taken and the serum was obtained following centrifugation. In that serum sample $\alpha$-GST level was determined quantitatively by ELISA method with ELISA kit test by CUSABIO (CSB-E08906h).

\section{Statistical analysis}

The collected data were processed using the statistical program SPSS 20 and the following statistical methods: Attributive statistical series were analyzed by determining percentages. Numerical series were analyzed with central tendency measures and with data dispersion measures. Statistical significance of the probability between numerical series was determined using Student's t-test. The probability of association between the distributions of the frequencies of two attributive variables was estimated by Fisher exact two tailed test. The results are shown in tables and figures.

\section{Results}

The analysis included 23 hospitalized infants from birth to 6 months of age with a diagnosis of acute gastroenteritis, divided in two groups. The first group included 7 (30.4\%) infants and the second group included 16 (69.6\%) infants, divided by age expressed in months and type of nutrition.

Table 1 presents the infants with acute gastroenteritis by gender and age.

Table 1: Distribution of the infants according to the gender and age

\begin{tabular}{|c|c|c|c|c|}
\hline Group & 1 & & II & \\
\hline Gender & Number & $\%$ & Number & $\%$ \\
\hline Male & 4 & 57.1 & 9 & 56.25 \\
\hline Female & 3 & 42.9 & 7 & 43.75 \\
\hline Age in months & Number & Mean ! SD & Number & $\begin{array}{l}\text { Mean ! SD } \\
34 ! 1454877\end{array}$ \\
\hline
\end{tabular}

The average infant age in the first group was $2.1 \pm 0.9$ months and in the second group was $3.4 \pm 1.5$ months.

Rotavirus was positive in 12 stool samples. In the first group, Rotavirus was positive in one (14.3\%) infant and in the second group Rotavirus was positive in $11(68.75 \%)$ infants. In one infant from the 
second group was isolated Shigella flexneri and in one infant from the same group was isolated Adenovirus (Figure 1).

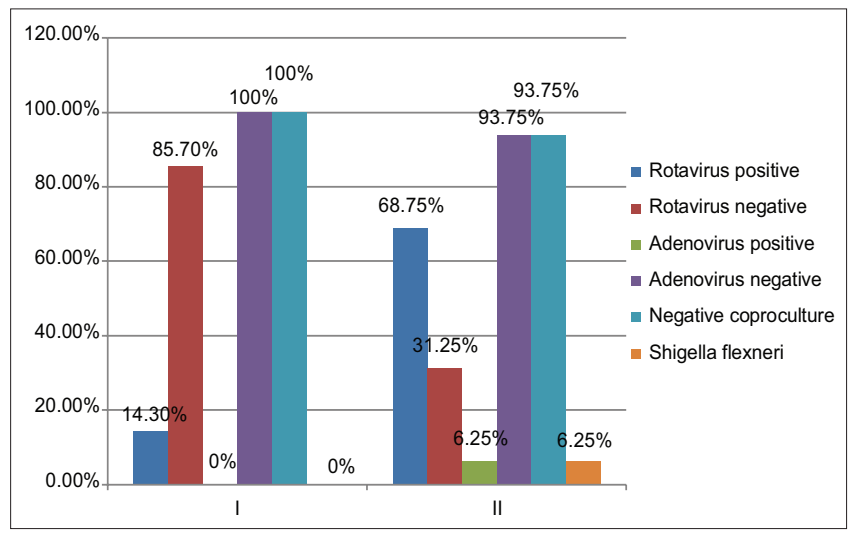

Figure 1: Microbiological findings in stool

$\alpha$-GST in serum was positive in 16 infants $(69.6 \%)$ from the whole of infants. In the first group, positive $\alpha$-GST in serum $(\geq 0.156 \mathrm{ng} / \mathrm{ml})$ was registered in only one infant $(14.3 \%)$ and in $85.7 \%$ it was negative. In the second group, $\alpha$-GST in serum was negative $(<0.156 \mathrm{ng} / \mathrm{ml})$ in one infant $(6.25 \%)$ and positive $(\geq 0.156 \mathrm{ng} / \mathrm{ml})$ in $93.75 \%$ of infants. A statistically significant association between group affiliation and serum $\alpha$-GST test for $p<0.05$ ( $p=0.000460$ ) was confirmed (Table 2).

Table 2: Distribution of $\alpha-G S T$ positive and $\alpha-G S T$ negative infants

\begin{tabular}{llllll}
\hline Group a GST & $\mathrm{I}$ & & & II & \\
\cline { 2 - 3 } & Number & $\%$ & & Number & $\%$ \\
\hline Negative & 6 & 85.7 & & 1 & 6.25 \\
Positive & 1 & 14.3 & & 15 & 93.75 \\
\hline a-GST: Alpha glutathione S-transferase. & & & &
\end{tabular}

The mean value of $\alpha$-GST in serum in infants diagnosed with acute gastroenteritis in the first group was $0.1 \pm 0.03 \mathrm{ng} / \mathrm{ml}$ and in the second group it was 6.2 $\pm 4.5 \mathrm{ng} / \mathrm{ml}$, the difference between the mean values was statistically significant for $p<0.05(p=0.002260)$ (Figure 2).

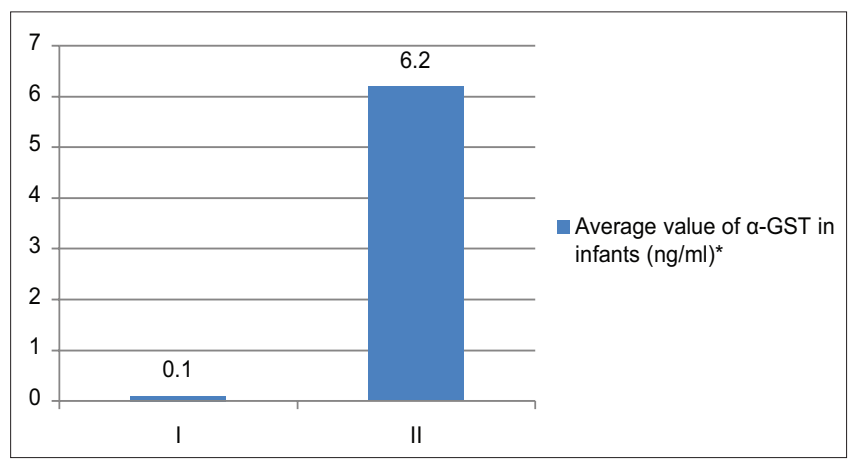

Figure 2: Average value of alpha glutathione S-transferase in infants with acute gastroenteritis. $\alpha$-GST: Alpha glutathione S-transferase; t-test $=-3.47531 ; p=0.002260$

Of the 16 infants with acute gastroenteritis who had positive alpha GST values in serum, 12 had Rotavirus (75.0\%) (Figure 3).

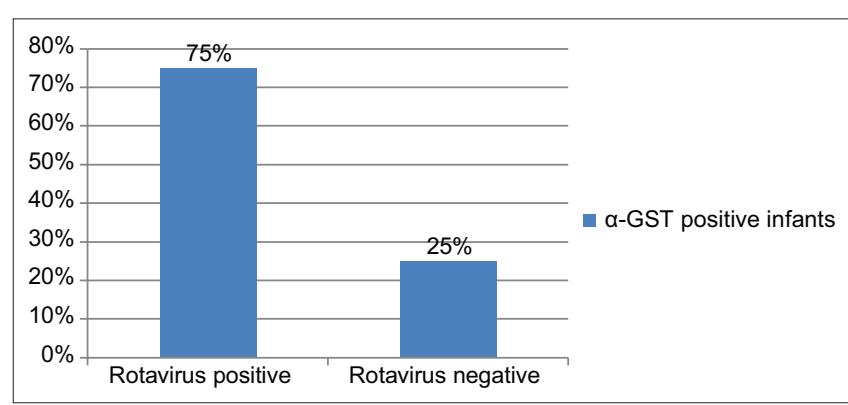

Figure 3: Distribution of Rotavirus in $\alpha$-GST positive infants. $\alpha$-GST: Alpha glutathione S-transferase

\section{Discussion}

Serum biomarkers that reflect damage of the intestinal mucosal barrier have been identified in several clinical and animal studies [4]. Peters et al. 1989 [8] and Khurana et al. 2002 [9] examined the activity of GST enzymes in the small and large intestines and proved that intestinal epithelial cells have a high content and activity of cytosolic GST and when the cell membrane of intestinal epithelial cells is damaged, these enzymes are released and their serum levels correlate with the degree of intestinal epithelial damage. According to Kong et al. 2019 [4] and Coles et al. 2002 [7], $\alpha-G S T$ is isoform of GST enzymes and is a highly active structural enzyme in intestinal mucosal epithelial cells. $\alpha$-GST is a potential biomarker for intestinal epithelial damage for a variety of reasons such as gastroenteritis, intestinal ischemia, and chronic inflammatory bowel disease. It can be used as screening in patients at risk for intestinal pathology [9], [10], [11]; in this study, the level of serum $\alpha$-GST in infants with acute gastroenteritis was determined, comparing patients on different type of milk nutrition. A statistically significant association between group affiliation and serum $\alpha$-GST test was registered for $p<0.05$. As for the mean value of serum $\alpha$-GST, it was also observed a statistically significant difference between the first and second group $(p<0.05)$. The results from this study showing striking difference in the level of $\alpha$-GST could be related to the study of van Oudheusden et al. 2013 [12] where it was described that enterocytes are rapidly degraded in the early stages of intestinal damage and this can be easily detected by determining the $\alpha$-GST values in plasma taking it as a marker for early detection of intestinal damage. In the study of Sherif et al. 2015 [13], GST was significantly positive in cases that were Rotavirus positive compared to those that were Rotavirus negative. Very similar results were obtained in this study. Rotavirus was detected in 12 infants whereas only one infant was on exclusive breastfeeding. Furthermore, majority of the infants with positive $\alpha$-GST values in serum had Rotavirus in their 
stool. These findings might suggest that Rotavirus can cause erosion of the intestinal epithelium producing higher levels of $\alpha$-GST in Rotavirus positive cases. The available literature during this research showed only few studies conducted on infants with acute gastroenteritis in which the serum concentrations of $\alpha$-GST originating from the intestinal epithelium were examined. For performing systematic review and getting more significant evidence based conclusions, more studies, higher number of participants, and follow-up over a longer period of time are necessary.

\section{Conclusion}

In this study, it was found that $\alpha$-GST is a biomarker for early intestinal epithelial damage in infants primarily with Rotavirus acute gastroenteritis. $\alpha$-GST serum values were significantly lower in infants who were exclusively breastfed compared with infants who were not exclusively breastfed.

This biomarker can serve as good early indicator of intestinal epithelial damage especially in pediatric intensive care units, thus preventing further damage and save the epithelial integrity as early as possible. In some patients can timely indicate cessation of enteral feeding and preserving the intestinal epithelium.

\section{References}

1. Sdiri-Loulizi $K$, Gharbi-Khélifi $H$, de Rougemont $A$, Chouchane S, Sakly N, Ambert-Balay K, et al. Acute infantile gastroenteritis associated with human enteric viruses in Tunisia. J Clin Microbiol. 2008;46(4):1349-55. https://doi.org/10.1128/ jcm.02438-07

PMid: 18287312

2. Guarino A, Ashkenazi S, Gendrel D, Vecchio AL, Shamir R, Szajewska H. Evidence-based guidelines for the management of acute gastroenteritis in children in Europe: Update 2014. J Pediatr Gastroenterol Nutr. 2014;59(1):132-52. https://doi. org/10.1097/mpg.0000000000000375

PMid:24739189

3. Grootjans J, Thuijls G, Verdam F, Derikx PM, Lenaerts K, Buurman AW. Non-invasive assessment of barrier integrity and function of the human gut. World $\mathrm{J}$ Gastrointest Surg. 2010;2(3):61-9. https://doi.org/10.4240/wjgs.v2.i3.61

PMid:21160852
4. Kong C, Shu-Min L, Yang H, Wei-Dong X, Yun-Yun C, Wu Y, et al. Screening and combining serum biomarkers to improve their diagnostic performance in the detection of intestinal barrier dysfunction in patients after major abdominal surgery. Ann Transl Med. 2019;7(16):388. https://doi.org/10.21037/ atm.2019.07.102

PMid:31555702

5. Sherratt JP, Hayes DJ. Glutathione S-transpherases. In: loannides C, editor. Enzyme Systems that Metabolise Drugs and Other Xenobiotics. $1^{\text {st }}$ ed. New Jersey: John Wiley and Sons Ltd.; 2001. p. 319-52. https://doi.org/10.1002/0470846305.ch9

6. Kelly N, Friend K, Boyle P, Zhang XR, Wong C, Hackam DJ, et al. The role of the glutathione antioxidant system in gut barrier failure in a rodent model of experimental necrotizing enterocolitis. Surgery. 2004;136(3):557-66. https://doi. org/10.1016/j.surg.2004.05.034

PMid:15349102

7. Coles FB, Chen G, Fkadlubar F, Radominska-Pandya A Interindividual variation and organ-specific patterns of glutathione S-transferase alpha, mu, and pi expression in gastrointestinal tract mucosa of normal individuals. Arch Biochem Biophys. 2002;403(2):270-6. https://doi.org/10.1016/ s0003-9861(02)00226-6

PMid: 12139976

8. Peters $\mathrm{WH}$, Roelofs HM, Nagengast FM, van Tongeren $\mathrm{JH}$. Human intestinal glutathione S-transpherases. Biochem J. 1989;257(2):471-6. https://doi.org/10.1042/bj2570471 PMid:2930461

9. Khurana S, Corbally MT, Manning F, Armenise T, Kierce B, Kilty C. Glutathione S-transferase: A potential new marker of intestinal ischemia. J Pediatr Surg. 2002;37(11):1543-8. https:// doi.org/10.1053/jpsu.2002.36181

PMid:12407536

10. McMonagle MP, Halpenny M, McCarthy A, Mortell A, Manning F, Kilty $\mathrm{C}$, et al. Alpha glutathione S-transferase: A potential marker of ischemia-reperfusion injury of the intestine after cardiac surgery? J Pediatr Surg. 2006;41(9):1526-31. https://doi. org/10.1016/j.jpedsurg.2006.05.017

PMid:16952586

11. Delaney CP, O'Neill S, Manning F, Fitzpatrick JM, Gorey TF. Plasma concentrations of glutathione S-transferase isoenzyme are raised in patients with intestinal ischaemia. $\mathrm{Br} J$ Surg. 1999;86(10):1349-53. https://doi. org/10.1046/j.1365-2168.1999.01245.x

PMid:10540149

12. van Oudheusden $R T$, Aerts $A B$, Ignace $H H$, Misha LD Challenges in diagnosing adhesive small bowel obstruction. World J Gastroenterol. 2013;19(43):7489-93. https://doi. org/10.3748/wjg.v19.i43.7489

PMid:29632988

13. Sherif LS, Raouf RK, El Sayede RM, El Wakkadd AS, Shoaib AR, Ali $\mathrm{HM}$, et al. Glutathione transferase as a potential marker for gut epithelial injury versus the protective role of breast milk slgA in infants with rota virus gastroenteritis. Open Access Maced J Med Sci. 2015;3(4):676-80. https://doi.org/10.3889/ oamjms.2015.125

PMid:27275307 